www.jmscr.igmpublication.org

Impact Factor (SJIF): 6.379

Index Copernicus Value: 79.54

ISSN (e)-2347-176x ISSN (p) 2455-0450

crossrefDOI: https://dx.doi.org/10.18535/jmscr/v6i9.163

Journal Of Medical Science And Clinical Research

IGM Publication

An Official Publication of IGM Publication

\title{
A U-Shaped Metallic Foreign Body in the Nasopharynx of an Infant- A Case Report \\ Authors
}

\author{
Chijioke C Anekpo ${ }^{1 *}$, Anthony J Edeh ${ }^{2}$ \\ ${ }^{1}$ Department of Ear Nose and Throat Enugu State University Teaching Hospital Parklane Enugu \\ ${ }^{2}$ Department of Surgery Enugu State University Teaching Hospital Parklane Enugu \\ *Corresponding Author \\ Chijioke C Anekpo \\ Email: cckpne@gmail.com
}

\begin{abstract}
Foreign body $(F B)$ in the nasopharynx in Ear, Nose and (ENT) clinics is rare as opposed to foreign bodies in the ear and nose. It is likely to be missed initially. A high index of suspicion is required for the diagnosis ${ }^{l}$.

We report a case of $U$-shaped metallic foreign body lodged in the nasopharynx of an infant. The foreign body was diagnosed by plain radiography skull views including the nasopharynx. It was removed under general anaesthesia via the oral route without complications.
\end{abstract}

\section{Introduction}

From personal experience inhaled or ingested foreign bodies rarely lodge in the nasopharynx. However foreign body in the nasopharynx commonly follows insertion through the nasal cavity but foreign bodies in the oral cavity or oropharynx into the nasopharynx are less common $^{2}$.

Nasopharyngeal foreign bodies usually are asymptomatic and therefore may be undetected for weeks. The diagnosis may be missed when symptoms manifest except one has a high index of suspicion. In contrast, foreign bodies in the laryngo tracheobronchial airway are emergencies and usually present with chocking spells and difficult with breathing hence early presentation to the hospital. ${ }^{3}$ Foreign bodies in the oropharynx also cause early symptoms of drooling of saliva in infants and young children or odynophagia, dysphagia or aphagia in older children. In both age groups compression of the trachea or larynx can cause dysphea, wheezing or persistent cough. ${ }^{4}$ Children are prone to explore their environment. They have a high tendency to inhale, ingest or insert any material into the natural orifics. It is very difficult to examine the nasopharynx especially in children ${ }^{5}$

The use of nasal endoscopes has revolutionized the otolaryngologist ability to visualize not only the intranasal structures but also the nasopharynx, thus helping the surgeon to localize and remove the foreign bodies not visible on anterior rhinoscopy. ${ }^{6}$

Foreign bodies in the nasopharynx is very important because it is rare and the region is clinically inaccessible on routine ENT examination. 


\section{Case Report}

A nine month old child was referred to us from an X-ray center with a complaint of foreign body visible in a plain radiography. Initially the child was taken to a peripheral hospital with a history foreign body ingestion while playing with a plastic towel peg. The mother became suspicion when she could not find the mettallic component of the peg while the child was crying excessively with associated cough, dropping saliva but no dysphonia.

Examination revealed a restless child, dropping saliva afebrile to touch and not in any respiratory distress. Both anterior and posterior rhinoscopy were not done.

Accompanying plain radiograph of Neck, Chest and Abdomen done showed a U-shaped radio opaque foreign body in the nasopharynx. This was best demonstrated in the lateral radiograph. Fig (1).

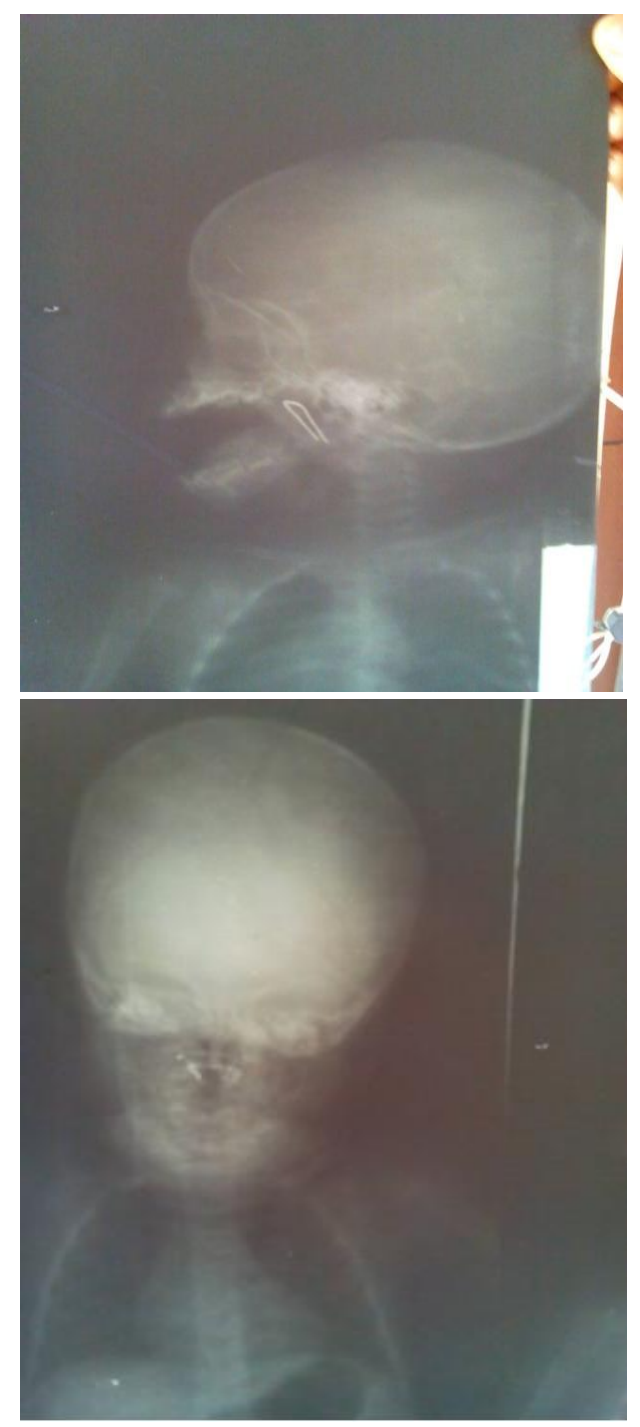

Patient was taken to the theatre, under general anaesthesia with endotracheal intubation, nasopharynx was exposed by traction of the soft palate with catheter. A U shaped metallic foreign body was removed with forcep. (fig. 2).

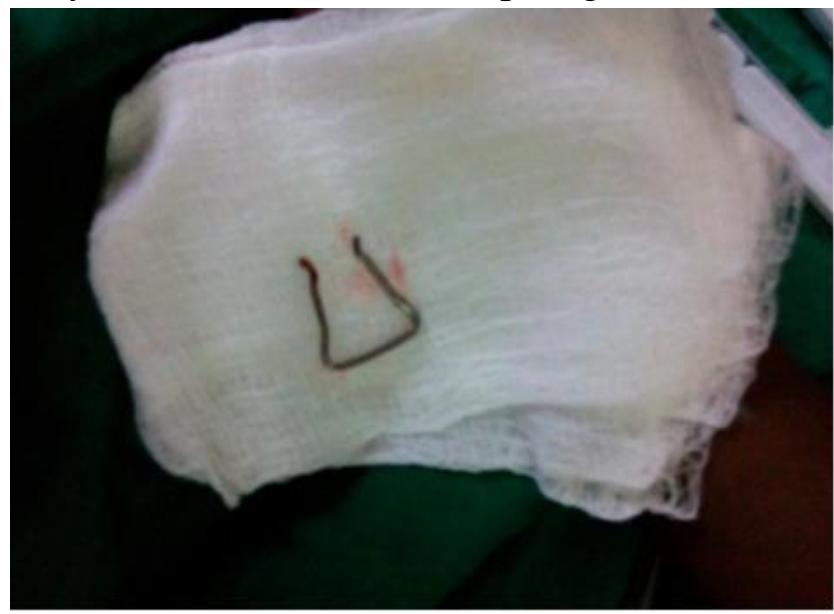

Completed plastic peg (Fig 3)

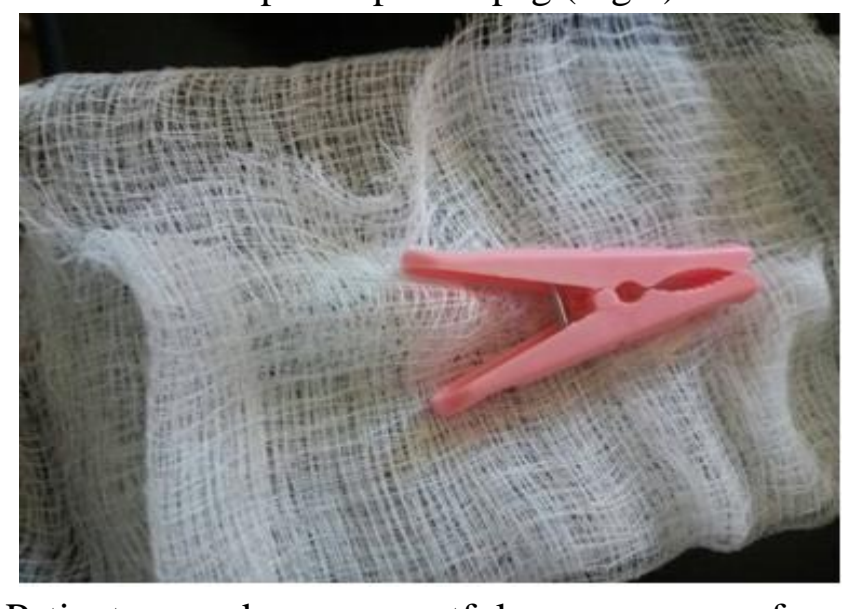

Patient made uneventful recovery from anaesthesia and was discharged the same day on antibiotic, analgesic and nasal decongestant

\section{Discussion}

Although foreign bodies in nasopharynx are uncommon, metallic or opaque foreign body are easily identified on plain radiograpy of the nasopharynx as seen in this index case. Irregular object in the pharynx appear to lodge in the tonsils vallecula or pyriform sinuses while round or ovoid object are found more in the opening of esophagus or cricopharyngeal muscle. It is difficult to examine the nasopharynx in children hence quick radiological investigation may confirm the exact location of the foreign body and suggest the method of removal. Successful removal of any 
foreign body requires adequate visualization especially in nasopharynx. ${ }^{7}$

Endoscopy provide proper visualization especially for sharp foreign body which may cause damage to the surrounding tissue during removal. Other methods of removal include fluoroscopy, or use of a magnet as possible means of removal of sharp metallic objects. ${ }^{8}$ These are not available in our centre at the moment. In this case, retraction of soft palate with catheter, exposed the nasopharynx and the foreign body was removed with magil's forces without complication.

Other foreign bodies reported in the nasopharynx include yam, animate foreign bodies such as leeches can get to the nasopharynx through the nose or a round worm can get lodged in the nasopharynx during vomiting, big metallic nut, laryngoscope bulb, coin and metallic ring. ${ }^{9-11}$

A foreign body taken orally rarely ascends in the nasopharynx due to a variety of reason. This include digital manipulation as reported in cases of yam and big metallic nut, regurgitation due to vomiting or coughing, if the foreign body is put into the mouth in lying down position with the extended neck, as it makes the nasopharynx dependent. ${ }^{10}$

The study noted that because of the spring like nature of the U-sharp metallic foreign body, the tendency to move up to the nasopharynx once ingested cannot be over looked.

\section{Conclusion}

Foreign body in the nasopharynx of a child is quite uncommon. This study noted another reason why foreign body taken orally can lodge in the naasopharynx if it is spring like in nature. Early intervention which include urgent radiography of the nasopharynx, neck, chest and abdomen is very important. This will help to localize the foreign body and its nature. Once located early removal is recommended usually under GA in the operating theatre.

\section{References}

1. NN Dulta, Bhaben, Choudhury. An unusual foreign body in the nasopharynx.
India Journal of otolaryngoloy/Head and Neck surgery.2005 July 57(3) 266-267.

2. Kansara A.H, Ramesh D.K. Unusual foreign body in the nasopharynx and ethmoidal sinus. Indian Journal of Otolaryngology,\& Head-Neck Surgery 1999 August 71-73.

3. Poona Marwah, Adhi Arya, Vidushi Mahayan. Laryngoscope Bulb. An unusual foreign body in Nasopharynx Indran Journal of Peadiatric vol. 81. Nov. 2014.

4. Rowe.D,L: Otolaryngology-Head and Neck Surgery.Way, Wh and Doherty, GM(Editors).Current Surgical Diagnosis and treatment, 11Edition 2003,Chapter 39:pp 989-990

5. FASUNLA A.J, OLOMA S, OSUKOYA A,AKENROYE M.I. Foreign body in the nasopharynx mimicking obstructive adenoid, Jos journal of medicine.2013 Vol 7 N0. 2

6. Onakoye PA, Adoga AA, Adoga AS.Galadima C, Nwaorgu OG. Anunusual rhinopharyngeal foreign body.West Afri $\mathrm{J}$ Med.2005 vol $24,89-99$

7. Parker AJ, Bingham BJ, Osborne JE. The swallowed foreign: Is it in the nasopharynx. Postgraduate Medical Journal of UK (1988) vol 68,201-203.

8. Senguta, A, Saha, $\mathrm{P}$, and Chakrabarty, S Foreign body in the nasopharynx of a child. Indian Journal of Otorlaryngology, Head and neck surgery 2005 vol 57 issue 3 pp248-249.

9. MM Sangeela, RS Greval, D Sing. Paediatric nasopharyngeal foreign bodies. Indian J Otolarynology, Head and Neck Surgery.1999 51(1)80-82

10. Oguta F, Bereketoglu M, Bilgen C, Totan. A metal ring that had been lodged in the child's nasopharynx for 4yrs.Ear Nose and Throat journal 2001,80(8) 520-2

11. Raahat ZM. Coin in nasopharynx in a young child. Journal of the college of physician and surgeons Parkistan 2003 13(4) 235-236. 